\title{
The Role of Cognitive Linguistics in Promoting the Language Research
}

\author{
Dapeng WANG \\ Teaching and Research Institute of Foreign Languages \\ Bohai University \\ Jinzhou,Liaoning, 121013 China
}

\begin{abstract}
Cognitive Linguistics of language is built on the basis of our experience of the world above. Cognitive Linguistics has a profound reflection and re-recognition for some traditional language problems, and put forward new insights and explanations. Shift from objectivist view of cognition and language to empirical view of cognition and language marks the progress of human knowledge and the study of language philosophy.
\end{abstract}

Keywords- Cognitive Linguistics, research and development, promotion

\section{INTRODUCTION}

Cognitive Linguistics is a new paradigm in linguistics; it contains many different theories, methods and researches. Cognitive Linguistics began in the 1970s, after mid-1980s, it extended the scope of its research into many areas of linguistics, such as syntax, meaning, phonology and discourse and so on. The important sign of maturity is the first international conference of cognitive linguistics in the spring of 1989, held in Duisburg, Germany, and the magazine of "cognitive linguistics" published in 1990. From the date of birth, cognitive linguistics put them in this major discipline of cognitive science, forged a bond with philos ophy, psychology, anthropology, computer science and neuroscience, and gradually become a "school of learning" in Contemporary Linguistics.

\section{INTRODUCTION TO COGNITIVE LINGUISTICS}

Cognitive linguistics, suggests that it is the study of human / brain cognition and how the language is closely related to science. About the rise of cognitive linguistics professor George Lakoff, one of the founders of the theory in an interview with John Brockman said these words:

In 1975, I became acquainted with certain basic results from the various cognitive sciences pointing toward an embodied theory of mind - the neurophysiology of color vision, prototypes and basic-level categories, Talmy's work on spatial relations concepts and Fillmore's frame semantics. These results convinced me that the entire thrust of research in generative linguistics and formal logic was hopeless. I set about, along with Len Talmy, Ron Langacker, and Gilles
Fauconnier, to form a new linguistics - one compatible with research in cognitive science and neuroscience. It is called Cognitive Linguistics, and it's a thriving scientific enterprise.

\section{DESCRIPTION AND ANALYSIS OF THE LANGUAGE DEFINITION}

Linguistics, language teaching (including foreign language teaching) is required for the language definition. Course of things should first define the nature of the things, analyze its characteristics, and finally may give its definition. The defined language definition mainly related to three properties of language, which has three different versions.

A. Tools say

Language is a unique universal human capacity. Language is mankind's most important communication tool and thinking tool, is aware of the internal, mental and spiritual movement, status and relationship with sound expression. Language is ability, a brain-specific mechanism.

\section{B. Ideological say}

The ancient Greek philosopher Aristotle said: "Language is the experience of the performance of various categories of thought." Inspired by linguists in European Renaissance also believe that talking is the expression of ideas. Man as a rational, thinking animal is to create a language to express ideas. British linguist $\mathrm{H}$ - Sweeten said: "Language is the expression of the concept; it is composed of words by voice, then this combination of words to form sentences. The form adapts to a combination of many concepts of ideas."

\section{Symbols say}

Language is the symbol to express thought, is generated by the use of any symbol system to express thoughts and feelings and aspirations, it is not depend on the form or the actual performance of the formula. Language is a sound symbol system that to make any social group coherent internally.

These classical studies', including some of the other statements, such as the view that language is part of cultural carrier or culture, are on the birth of language studies and has made a significant contribution to linguistics. However, we believe that these statements are only certain features of the language description, not a comprehensive overview of the 
language; at least, these statements are still further expanded as necessary.

From the Tools saying, this kind of role or function from things to define things is actually a description of the extension. Like physics, chemistry is the tools to understand the world, and fundamental physics does not explain what the chemical is. From the ideological point of view says, this definition emphasizes too much on thinking. The symbols saying is too casual and broad, lack of the necessary specifications and tight. In conclusion, the study of language definition does not end there.

\section{BEGIN AND DEVELOPMENT OF LANGUAGESRESEARCH}

\section{A. The rise of philology}

With language, people can express and record. So there are books, from generation to generation, to become a classic. In order to facilitate future generations of people to read through these classic, someone came out to explain, thus creating philology, which is an early form of linguistics. Changing the language from the object of worship to the object of study (or the object of worship and studies ) is a big step forward. To read through ancient books and produce philology, which is same aspect for China and Western countries - - India, Greece, Rome, the same, but different forms and manifestations. Western countries are using a phonetic system, China is using Chinese characters.

Chinese philology focuses on the complex relationship between the shape, sound and meaning of the characters. Philological works roughly have four forms: added pronunciation and meaning of words; arranged by radical words; arranged by rhyme; listed by literal meaning.

In addition to meaning of words, Western philology pays special attention to the words of the morphological changes, because it is crucial for the understanding of statement. So they produced grammar school very early. Whether Chinese in ancient times had some form of change, there is no conclusion, at least not reflected in the shape of Chinese characters. Integrated words into sentences, and not difficult to understand, therefore, there is no formed grammatical subject in Chinese philology.

\section{B. Go towards Linguistics}

The development of philology to linguistics, there are several aspects of the change. Focus of the study from ancient to modern, from text to go to the language. To increase the study of modern languages to its right place, and to recognize spoken language is the key to written language, whether in China or in the West, are recent thing. Scope of the study from the minority language extensions to multiple languages, in the past, Chinese scholars studied Chinese, Indian scholars limited studied Sanskrit, Western scholars only study Greek. There are many people in the study of a variety of languages, not limited to the country or the nation's scholars. Many comparative study of language make more in-depth understanding of the language. Systematic knowledge has been fragmented. In the West, the French scholars in 17th century wrote the "rational grammar", lin ked the syntax and logic. Scholars in 19th century developed a historical comparative study. From the early years of the 20th century onwards, the internal laws of the study of language has made significant progress, new theories abound. Study of language completely gets rid of the fetters for the service of literature, philosophy, and history. Language studies in China are no longer a dependency.

\section{COGNITIVE LINGUISTICS AND COGNITIVE RESEARCH OF LANGUAGES}

History and Philology cognitive research can be traced back a long time ago, but the rise of cognitive linguistics is in the recent two or three decades. Cognitive study of language can be divided into two aspects: First is the psychological approach, the second is the linguistic approach. Researches based on the psychology focus on language perception, language comprehension, memory, attention, reasoning, etc., and the studies based on linguistics focus on the form of language, the meaning of the language symbols, operations between form and meaning, conceptual link with the outside world and other issues. Cognitive study of language involves a fundamental question, that is what is the language and what way and structure do the language in exist.

About what language is, there are different views, basically fall into two categories: one believes that language is an objective phenomenon, which is independent of the human mind, it can be used as a purely objective study (objectivism); another believes that language and the human mind has an interdependent relationship, not a purely objective phenomenon, the study of language must exist in the mind (non-objectivism). This problem is a fundamental linguistic issue. Unlike other disciplines of linguistics, the study has been sticking with other disciplines. Saussure has mentioned materials and tasks of linguistics: "First, the linguistic material is composed of all the expression of human speech activities." So what contents do the expression of human speech activities include? First of all is the language itself because human speech activity is built on the basis of language. So what is language should be answered first. So far, the writings of various non-linguistics and linguistics have dozens of definition of "language" from different viewing angles. Saussure noted that the multifaceted study of linguistics and what's the different part of linguistics from other disciplines is the multiple properties of objects? How can we find a complete object of linguistic study? We can begin to solve the problem from many aspects of it, but "we could not find complete object of linguistics anywhere; everywhere will encounter such a dilemma: either only obsessed one aspect of each issue, braving the dangers of unseen the above duality; or from the same time to study several aspects of this speech. In this way, the object of linguistics is a mess of a bunch of bizarre, something no contact with each other. ". Cognitive Linguistics takes language as a non-self-sufficient cognitive networks, the cognitive network includes form category, the concept of the system, the relationship between expression systems and knowledge systems. 


\section{ROLE IN PROMOTING COGNITIVE LINGUISTICS}

\section{A. To establish "one to one" mapping relations between the semantic and syntactic}

A basic theory of cognitive linguistics claims that there is a one to one mapping between semantics and syntax. This thesis consists of the following two meanings:

Any two different configurations of the different syntax elements will inevitably have different semantic value, any different semantic structures are corresponding to different grammatical structures; any grammatical marker has its own semantic value. This is stark contrast with Chomsky's transformational-generative grammar. Generative grammar emphasizes transformation between the structures, format conversion only pay attention to the legitimacy of format, but pay no attention to the semantic value and syntax formats before and after the transformation. In addition, in the formal school pays attention to linear structure, but largely ignored the existence of colorful language syntax markers. Ironically, the formal school on the one hand turned a blind eye to these living grammatical markers and on the other hand theoretically man-made many "zero marks." We feel that the principle of cognitive linguistics is justified. So far we have not found that two different grammatical structure and meaning of the expression are exactly the same, but could not find any grammatical marking not load semantic value.

\section{B. Cognitive processes influence choice of sentence}

Introducing dynamic cognitive processes to grammatical parsing, is another distinctive feature of cognitive linguistics. An object, due to the different cognitive viewpoints, will affect people choose a different sentence to express. Cognitive Linguistics Cognitive called this phenomenon of the interaction of perspective transformation and the selection of the language structure "construal". For example, put a half glass of water in front of the cup, because different people have different viewing angles, they will select a different sentence.

\section{CONCLUSION}

Language study should be an integral part of the study of the mind and the human brain. Linguistics is a part of cognitive psychology, and ultimately will be an integral part of biology. Language must be in the form of language as the entering point, then with the language meaning, this important substantive aspect, to finalize the radical recognition of the generation and operation of the language mechanisms of human brain. Linguistics is currently working and gradually close together with other disciplines such as computer, medical science, sociology. However, linguistics is often only a vassal of other disciplines, and most researches lag behind other disciplines. Today, linguistics should face the reality, to use the only way of language study and with the help of other disciplines in order to achieve our ultimate goal of understanding the nature of human language.

\section{REFERENCES}

[1] Liuzhengguang. Cognitive linguistics, language acquisition concept [J]. Foreign Language Teaching and Research,2009,01:46 -53 +81.

[2] Shu Dingfang Chinese Cognitive Linguistics two decades - Review and Reflection [J] Modern Foreign, 2009,03:248-256 +328-329.

[3] Shaoshaoquan. Linguistics Cognitive Chinese English majors polysemy acquisition of [D]. Southwest University, 2009.

[4] Shi $\mathrm{Yu}$ - zhi. linguistics of "power" and "over" [J]. Foreign language (Shanghai International Studies University),2004,02:21-33.

[5] Wangyin Embodied cognitive linguistics, I see the [J]. PLA UNIVERSITY OF FOREIGN,2004,05:1 -5.

[6] Duan Yun. Cognitive linguistics language speech act force [D]. Southwest University, 2011. 